\title{
Foreign Capital, Processing Incentives, and Urban Unemployment
}

\author{
John Gilbert \\ Utah State University \\ Thomas Wahl \\ Washington State University
}

\begin{abstract}
We use a general equilibrium model of a small developing economy with urban unemployment to illustrate the impact of processing incentives in the presence of foreign owned factors of production. We show that the location of the processing industry plays a crucial role in determining whether or not processing incentives will raise welfare through employment effects, but, once stability conditions are imposed, does not alter the positive investment terms-of-trade effect resulting from foreign ownership of resources.
\end{abstract}

- JEL Classifications: F13, F21, J60

- Key Words: foreign capital, processing, unemployment

\section{Introduction}

In many small economies that depend heavily on the export of raw materials, we can find policies designed to restrict those exports for the purpose of developing processing capabilities. Where those policies do not exist, we can invariably find calls for their institution. It is widely perceived that by exporting

\footnotetext{
*Corresponding address: John Gilbert, Assistant Professor, Department of Economics Utah State University, 3530 Old Main Hill Logan, UT 84322-3530. Tel: +1-435-797-2314, Fax: +1-435-797-2701, E-mail: jgilbert@econ.usu.edu

Thomas Wahl, Associate Professor, Department of Agricultural Economics Washington State University PO Box 646210 Pullman, WA 99164-6210, Tel: +1-509-335-5547, Fax: +1-509-335-1173, E-mail: wahl@wsu.edu (2002-Center for International Economics, Sejong Institution, All Rights Reserved.
} 
raw materials these countries are not performing to their full potential, and that promoting value-added exports should be encouraged. A well-known example is Indonesia, which has banned log exports since 1978. By 1986 over 100 plywood mills were established. In 1988 it went further by imposing large taxes on sawn timber exports, which were scaled down depending on the degree of further processing of the export product. Almost all of the major Asian log producing countries have followed suit.

Standard models of trade provide no justification for export restrictions of this type. However, it might be argued that institutional features peculiar to developing economies can provide a justification. In this paper we consider two possibilities. The first is that in many developing economies natural resources are controlled by foreign interests, opening up the potential for welfare-enhancing investment terms-of-trade effects, such as those explored by Bhagwati and Tironi (1980). In essence, by lowering the domestic return to a foreign-owned factor, trade policy may reduce the transfers out of the economy to foreign interests. The second is that the dual structure of developing economies itself provides a rationale for export restrictions i.e., that the employment (and therefore welfare) effects of processing incentives may be positive. We make use of a priceexogenous, mobile capital (neoclassical), Harris-Todaro (1970; henceforth HT) model with multiple levels of production to analyze these propositions.

The paper is related to a number of recent contributions to the extensive HT literature. Marjit et al. (1997) consider tariff-jumping foreign investment in the context of a HT model with intermediates and reach the surprising conclusion that, in contrast to the conventional argument of Brecher and Diaz-Alejandro (1977), tariff-jumping investment may not be immiserizing if it flows into an intermediate sector. However, they do not consider pre-existing foreign ownership. Chao and $\mathrm{Yu}$ (1992) consider issues relating to imported intermediates, while Chao and Yu (1999) have considered export promotion policy in a final-good only HT model. Dean and Gangopadhyay (1997) consider raw material export restrictions as a processing incentive, concluding that they worsen unemployment in the short run (and therefore welfare), but improve it in the long run. However, they do not consider either foreign ownership, or the location of the processing industry, both of which may have a significant impact on the effect of export restrictions. Gilbert and Wahl (2001) have considered location, but not in the context of a model with a natural resource-based intermediate industry. They also do not consider the potential effect of foreign-owned resources. 
In section 2 of this paper we set out the basic structure of our model. In sections 3 and 4 we consider the effect of export restrictions under two alternative scenarios. In the first, a (labor-intensive) processing sector is assumed to be located in the rural region. In the second, a (capital-intensive) processing sector is assumed to be located in the urban region. In both cases, a natural-resource based intermediate sector is located in the rural region, with the natural resource being foreign-owned. These two cases can be considered as archetypes of a developing economy with a natural-resource based processing sector. Use of these two archetypes is motivated by the requirements of stable equilibrium. A key result is that export restrictions raise welfare in the former case, and lower it in the latter, a consequence of the location of processing activities. However, in both cases we can confirm the validity of the Bhagwati-Tironi argument. Concluding comments and policy implications are discussed in Section 5.

\section{The Model}

We consider a three sector, dual economy. Good 1 is produced in the urban region using labor $(L)$ and capital $(K)$. Good 2, a pure intermediate, is produced in the rural region using labor and natural resources $(N)$, which are assumed to be owned by foreign interests. For simplicity we assume 100 percent ownership, but this does not alter our conclusions in any fundamental way. Good 3 is initially assumed to be produced in the rural region using labor, capital, and part of the output of sector 2. Production functions are continuous, linearly homogeneous, and strictly concave. Capital and natural resources are fully utilized, but labor is fully employed only in the rural region, where the wage $(w)$ is flexible. In the urban region, where the wage $(\bar{w})$ is fixed, there is unemployment. All goods are traded, and the small country assumption implies prices are exogenous. The trade pattern is such that good 1 is imported and goods 2 and 3 are exported. The social welfare function $\mu\left(Z_{1}, Z_{3}\right)$ is continuous, increasing in consumption $Z$ of good 1 and 3 , and quasi-concave. Perfect product markets and fixed factor supplies are assumed.

Equations (1)-(3) describe the zero profit conditions in terms of the unit cost functions, which can be solved for the factor prices $w, n$ and $r$ :

$$
\begin{gathered}
c_{1}(\bar{w}, r)=1 \\
c_{2}(w, n)=p_{2}
\end{gathered}
$$




$$
c_{3}\left(w, r, p_{2}\right)=p_{3}
$$

We let $p_{1}$ be the numéraire, and hence $p_{2}$ and $p_{2}$ can be interpreted as the domestic prices of goods 2 and 3, respectively, relative to good 1. By assumption, $\bar{w}$ is fixed in terms of $p_{1}$ only.

The HT hypothesis is that as long as the expected wage in the urban sector exceeds the wage in the rural sector, migration will occur. Labor market equilibrium requires that the rural wage equal the urban wage multiplied by the probability of obtaining a job in the urban sector. Hence:

$$
w=\pi \bar{w}
$$

where $\pi$ is the rate of employment in the urban sector (i.e., $\pi=L_{1} /\left(L_{1}+U\right)$ where $U$ is urban unemployed). Equation (4) can be solved for $\pi$. The partial derivatives of the unit-cost functions are the optimal factor input-output ratios, $a_{i j}$, by Shepherd's lemma. Therefore, factor market equilibrium requires:

$$
\begin{gathered}
a_{1 L} Q_{1}+\pi a_{2 L} Q_{2}+\pi a_{3 L} Q_{3}=\pi \bar{L} \\
a_{1 K} Q_{1}+a_{3 K} Q_{3}=\bar{K} \\
a_{2 N} Q_{2}=\bar{N}
\end{gathered}
$$

where $Q_{i}$ is output of good $i$, and a bar indicates the total stock of each factor. Equations (4)-(6) can be solved for output levels.

The budget constraint of the economy can be defined in terms of the GNP and expenditure functions. ${ }^{1}$ With foreign income fully repatriated:

$$
\begin{gathered}
G\left(p_{i}, \bar{K}, \bar{N}, L_{i}\right)+\left(p_{2}^{*}-p_{2}\right) X_{2}+\left(p_{3}^{*}-p_{3}\right) X_{3}-n N= \\
E\left(p_{1}, p_{3}, u\right) \quad i=1, \ldots, 3
\end{gathered}
$$

where a superscript $*$ designates a world price, and $X_{i}$ is exports of good $i$ (i.e., $\left.X_{i}=Q_{i}-Z_{i}\right)$. With export taxes $\left(t_{i}\right)$ in place, domestic and world prices will be related by $p_{i}\left(1+t_{i}\right)=p_{i}{ }_{i}, i=2,3$. Equation (8) can be solved for the level of social welfare. This completes our description of the initial equilibrium.

${ }^{1}$ The GNP function is defined: $G\left(p_{i}, \bar{K}, \bar{N}, L_{i}\right) \equiv \max \left\{\sum p_{i} Q_{i}-p_{2} Z_{2}: Q_{i} \in Y\right\} \quad i=1, \ldots, 3$, where $Z_{2}$ is intermediate use of good 2, and $Y$ is the production possibility set. Similarly, $E\left(p_{1}, p_{3}, u\right) \equiv \min$ $\left\{p_{1} Z_{1}-p_{3} Z_{3}: \mu\left(Z_{1}, Z_{3}\right) \geq u\right\}$, where $u$ is the target utility level. 


\section{Export Restrictions and Welfare}

In order to facilitate the subsequent analysis, we begin by deriving a general expression for the change in social welfare. Totally differentiating (8), making use of the definition of exports, yields:

$$
d W=\left(p_{2}^{*}-p_{2}\right) d X_{2}+\left(p_{3}^{*}-p_{3}\right) d X_{3}-\bar{N} d n+\bar{w} d L_{1}+w\left(d L_{2}+d L_{3}\right)
$$

where $d W \equiv E_{u} d u$. Utilizing (4) gives us:

$$
d W=\left(p_{2}^{*}-p_{2}\right) d X_{2}+\left(p_{3}^{*}-p_{3}\right) d X_{3}-\bar{N} d n+\bar{w} d L_{1}+\pi \bar{w}\left(d L_{2}+d L_{3}\right)
$$

We define the total labor-force in the urban area as $L_{U}$, so $d L_{1}=\pi d L_{U}+L_{U} d \pi$. Substituting into (10) we obtain:

$$
d W=\left(p_{2}^{*}-p_{2}\right) d X_{2}+\left(p_{3}^{*}-p_{3}\right) d X_{3}-\bar{N} d n+\bar{w} L_{U} d \pi
$$

where we have simplified by making use of the fact that $d L_{U}+d L_{2}+d L_{3}=0$. Thus the incremental change in welfare is broken down into three components. The first two terms are Harberger effects, the changes in exports across a price distortion. The second term is the investment terms-of-trade effect, the effect of changes in payments to foreign owned factors. The third term is the effect of changes in the probability of employment. As is well-known, free trade is suboptimal, since $d W \neq 0$ when $p_{i}=p_{i}^{*}$.

Now suppose that an export tax is imposed on good 2, with the objective of raising domestic processing. Assume that exports of good 3 are untaxed. Let $t$ be the export tax rate on good 2 (dropping the subscript), so that $p_{2}(1+t)=p_{2}^{*}$. Using this, and dividing both sides of (11) by $d t$ we have:

$$
\begin{gathered}
d W / d t=t p_{2}\left(d X_{2} / d p_{2}\right)\left(d p_{2} / d t\right)-\bar{N}\left(d n / d p_{2}\right)\left(d p_{2} / d t\right)+ \\
\bar{w} L_{U}\left(d \pi / d p_{2}\right)\left(d p_{2} / d t\right)
\end{gathered}
$$

To complete our analysis of the effect of the export tax, the sign of each of the terms in (12) must be determined.

PROPOSITION 1: An export tax on good 2 causes the return to natural resources to fall.

PROOF: Totally differentiating (1)-(3), holding the urban wage and other prices constant we obtain:

$$
\left[\begin{array}{ccc}
\theta_{1 K} & 0 & 0 \\
0 & \theta_{2 L} & \theta_{1 N} \\
\theta_{3 K} & \theta_{3 L} & 0
\end{array}\right]\left[\begin{array}{c}
\hat{r} \\
\hat{w} \\
\hat{n}
\end{array}\right]=\left[\begin{array}{c}
0 \\
\hat{p}_{2} \\
-\theta_{32} \hat{p}_{2}
\end{array}\right]
$$


where the $\theta_{i j}$ are cost shares, and a circumflex designates a proportional change (e.g., $\dddot{w}=d w / w)$. The solutions are:

$$
\begin{gathered}
\hat{r}=0 \\
\hat{w}=-\left(\theta_{32} / \theta_{3 L}\right) \hat{p}_{2} \\
\hat{n}=\left\{\left(\theta_{2 L} \theta_{32}+\theta_{3 L}\right) /\left(\theta_{2 N} \theta_{3 L}\right)\right\} \hat{p}_{2}
\end{gathered}
$$

The sign of (16) is unambiguously negative. As a specific factor, the return to natural resources is determined residually from $\hat{p}_{2}$ and $\hat{w}$. The rising wage and falling price of good 2 squeeze the natural resources return from both sides.

PROPOSITION 2: An export tax on good 2 raises the probability of finding urban employment.

PROOF: We have established the sign of the wage change in (15), and the sign of the change in the probability of employment follows immediately by differentiating (4) to obtain $\hat{\pi}=\hat{w}-\hat{\bar{w}}$. Since the wage rises, so does the probability of finding urban employment. The intuition behind this result is that the export tax on good 2 is in effect a subsidy to good 3. Production of good 3 rises, drawing labor from industry 2 and from the pool of urban unemployed, and thereby raising the ratio of urban employed to the total urban population.

PROPOSITION 3: In a stable equilibrium with fixed proportions technology, an export tax on good 2 causes net output of industry 2, and hence exports, to fall.

PROOF: We begin by determining the sign of the change in gross output of industry 2 . Since this industry uses only labor and the specific factor $N$, it follows directly from (7) that $\hat{Q}_{2}=-\hat{a}_{2 N}$. Utilizing $\sigma_{2}$, the elasticity of substitution between primary factors in sector 2 , and the cost minimization requirement this becomes:

$$
\hat{Q}_{2}=\theta_{2 L} \sigma_{2}(\hat{n}-\hat{w})
$$

which is negative using (15) and (16). Next we show that usage of good 2 in domestic processing has risen. Totally differentiating (5)-(7) holding $\bar{w}$ and factor endowments constant and expressing in percentage change form we have:

$$
\left[\begin{array}{ccc}
\lambda_{1 L} & \pi \lambda_{2 L} & \pi \lambda_{3 L} \\
0 & 1 & 0 \\
\lambda_{1 K} & 0 & \lambda_{3 K}
\end{array}\right]\left[\begin{array}{l}
\hat{Q}_{1} \\
\hat{Q}_{2} \\
\hat{Q}_{3}
\end{array}\right]=\left[\begin{array}{c}
\pi\left(\hat{\pi} \psi-\lambda_{2 L} \hat{a}_{2 L}-\lambda_{3 L} \hat{a}_{3 L}\right)-\lambda_{1 L} \hat{a}_{1 L} \\
-a_{2 L} \\
-\lambda_{1 K} \hat{a}_{1 K}-\lambda_{3 K} \hat{a}_{3 K}
\end{array}\right]
$$

where the $\lambda_{i j}$ are the proportion of factor $j$ employed in industry $i$ and $\psi$ is the proportion of labor in the urban area. The $\hat{a}_{i j}$ can be shown to be:

$$
\ddot{a}_{1 K}=-\theta_{1 L} \sigma_{1}(\ddot{r}-\hat{w})
$$




$$
\begin{aligned}
& \hat{a}_{1 L}=-\theta_{1 K} \sigma_{1}(\hat{r}-\hat{\bar{w}}) \\
& \hat{a}_{2 L}=-\theta_{2 L} \sigma_{2}(\hat{n}-w) \\
& \hat{a}_{2 L}=-\theta_{2 L} \sigma_{2}(\hat{n}-\hat{\bar{w}})
\end{aligned}
$$

where the $\sigma_{i}$ are the elasticities of substitution between primary factors in industry $i .^{2}$ In the case of industry 3 we have:

$$
\begin{aligned}
& \hat{a}_{3 K}=\theta_{3 L} \sigma_{K L}^{3} \hat{w}+\theta_{3} \sigma_{K K}^{3} \hat{r}+\theta_{32} \sigma_{K 2}^{3} \hat{p}_{2} \\
& \hat{a}_{3 K}=\theta_{3 L} \sigma_{L L}^{3} \hat{w}+\theta_{3 K} \sigma_{K L}^{3} \hat{r}+\theta_{32} \sigma_{L 2}^{3} \hat{p}_{2} \\
& \hat{a}_{32}=\theta_{3 L} \sigma_{L 2}^{3} \hat{w}+\theta_{3 K} \sigma_{K 2}^{3} \hat{r}+\theta_{32} \sigma_{22}^{3} \hat{p}_{2}
\end{aligned}
$$

where $\sigma_{i j}^{3}$ is the partial elasticity of substitution between inputs $i$ and $j$ in sector $3\left(\sigma_{i i}^{3}<0 ; \sigma_{i j}^{3}>0\right.$ if inputs $i$ and $j$ are competitive; $\sigma_{i j}^{3}<0$ if inputs $i$ and $j$ are complementary). Note that we have imposed symmetry conditions and $\hat{r}=\hat{\bar{w}}=0$. Substituting into (18) and solving yields:

$$
\hat{Q}_{3}=\frac{\lambda_{1 K} \pi\left\{\lambda_{2 L} \sigma_{2}(\hat{n}-\hat{w})-\hat{\pi} \psi\right\}-\lambda_{1 L} \lambda_{3 K} \hat{w}\left(\eta_{K L}^{3} \hat{w}+\eta_{K 2}^{3} p_{2}\right)+\pi \lambda_{1 K} \lambda_{3 L}\left(\eta_{L L}^{3} \hat{w}+\eta_{L 2}^{3} p_{2}\right)}{|\lambda|}
$$

where $|\lambda| \equiv \lambda_{1 L} \lambda_{3 K}-\pi \lambda_{1 K} \lambda_{3 L}$, and $\eta_{i j}^{3}=\theta_{3} \sigma_{i j}^{3}$ is the elasticity of demand for input $i$ with respect to the price of input $j .|\lambda|$ is negative by the Neary (1981) stability condition. Equation (19) can be broken down into four effects. The first represents the effect of labor released from industry 2 , the second the effect of labor pulled from the pool of urban unemployed, the third the cross effect between capital and intermediates, and the fourth the effect of substitution between labor and intermediates. Sufficient conditions to guarantee a rise in output of good 3 are that capital and labor, and labor and intermediates, are competitive, and that capital and intermediates are complementary. However, to simplify our analysis, and avoid the potential for perverse results from strong cross-effects, we impose fixed proportions technology in the use of intermediates (following Batra and Casas, 1973). This implies that $\hat{a}_{32}=0$ and $\sigma_{K 2}^{3}=\sigma_{L 2}^{3}=0$, and thus simplifies (19) to:

$$
\hat{Q}_{3}=\frac{\pi \lambda_{1 K}\left\{\lambda_{2 L} \sigma_{2}(\hat{n}-\hat{w})-\hat{\pi} \psi\right\}-\hat{w}\left(\lambda_{1 L} \lambda_{3 K} \eta_{K L}^{3}-\pi \lambda_{1 K} \lambda_{3 L} \eta_{L L}^{3}\right)}{|\lambda|}
$$

which must be positive.

We are now in a position to complete the welfare analysis:

PROPOSITION 4: Starting from free trade, in a stable equilibrium with fixed proportions

${ }^{2}$ These can be found by simultaneously solving the iso-cost/isoquant tangency condition with the definition of the elasticity of substitution in each industry (e.g. for industry 1 solving $\theta_{1 L} \hat{a}_{1 L}+\theta_{1 K} \hat{a}_{1 K}=0$ and $\left.\sigma_{1}=\left(\hat{a}_{1 K}-\hat{a}_{1 L}\right) /(\hat{\bar{w}}-\hat{r})\right)$. 
technology and with the processing industry located in the rural region, a sufficiently small export tax will raise welfare.

PROOF: From Propositions 1-3 above, and by definition, we know $d n / d p_{2}>0, d \pi / d p_{2}<0$, $d x_{2} / d p_{2}>0$; and $d p_{2} / d t=-p_{2} /(1+t)<0$. Hence $d w / d t$ in (12) is of indeterminate sign in general. However, $t=0$ if initially then $d W / d t>0$.

In summary, the processing incentive has three effects on welfare. The first is the familiar deadweight loss, but this is of second-order magnitude for a sufficiently small export tax it will be near zero. The other two terms are more important, and they both work in the same direction. The export tax lowers the returns to foreign owners of natural resources, thereby reducing payments out of the economy. Hence the result of Bhagwati and Tironi (1980) holds. The policy also increases the rate of employment, resulting in a more efficient use of the resources available to society. Starting from free trade therefore, an export tax will raise welfare. While optimal policy in the HT framework will involve a uniform wage subsidy (or the elimination of the wage distortion), the model does provide a justification for the commonly observed use of export restrictions to increase processing in developing economies, albeit a second-best one. Note also that this result holds even if foreign ownership is not assumed. The presence of foreign ownership augments the positive employment effect of the processing incentive.

\section{Urban Processing}

Now suppose that it is the processing activity that is located in the urban sector, not the import competing sector. Only equations (1), (3) and (5) of our model will differ, becoming:

$$
\begin{gathered}
c_{1}(w, r)=1 \\
c_{3}\left(\bar{w}, r, p_{2}\right)=p_{3} \\
\pi a_{1 L} Q_{1}+\pi a_{2 L} Q_{2}+a_{3 L} Q_{3}=\pi \bar{L}
\end{gathered}
$$

Using this system of equations, we obtain the following new results:

PROPOSITION 5: When the processing activity is located in the urban region, an export tax on intermediates will lower the rate of employment.

PROOF: Solving the amended system for the proportional changes in factor prices yields: 


$$
\begin{gathered}
\hat{r}=-\left(\theta_{32} / \theta_{3 K}\right) \hat{p}_{2} \\
\hat{w}=\left\{\left(\theta_{1 L} \theta_{32}\right) /\left(\theta_{3 K} \theta_{1 L}\right)\right\} \hat{p}_{2} \\
\hat{n}=\left\{|\theta| /\left(\theta_{3 K} \theta_{1 L} \theta_{2 N}\right)\right\} \hat{p}_{2}
\end{gathered}
$$

where $|\theta|=\theta_{3 K} \theta_{1 L}-\theta_{1 K} \theta_{2 L} \theta_{32}$. The result follows directly from (4) and (15a). Equation (15a) indicates that the processing incentive causes the wage rate to fall, and hence by (4) the probability of finding urban employment also falls. Intuitively, as $p_{2}$ falls, capital moves out of the rural area and into processing, causing a fall in the marginal product of rural labor and hence in $w$. Since $\bar{w}$ is constant, the expected wage in the urban region now exceeds that in the rural region, inducing a further migration of workers and swelling the ranks of the unemployed.

Comparison of (15) with (15a) indicates the crucial difference between the two archetypes-the change in the rural wage and hence employment rate effect takes the opposite sign. This result emphasizes the importance of location of the processing industry. Note also that factor intensity assumptions are not required for this result, as the sign of neither (15) nor (15a) depends on factor intensities.

PROPOSITION 6: In a stable equilibrium with the processing industry located in the urban sector, fixed proportions technology, and no foreign ownership, an export tax will lower domestic welfare.

PROOF: This result follows from application of (12). Since the probability of employment has fallen, the third term in (12) will have a negative impact on welfare, the opposite of the result obtained above. The change in gross output of the processing sector can now be shown to be:

$$
\hat{Q}_{3}=\frac{\pi \lambda_{1 K}\left\{\lambda_{1 L} \sigma(\hat{r}-\hat{w})+\lambda_{2 L} \sigma_{2}(\hat{n}-\hat{w})-\hat{\pi} \psi\right\}+\hat{r}\left(\lambda_{1 K} \lambda_{3 L} \eta_{L K}^{3}-\pi \lambda_{1 L} \lambda_{3 L} \eta_{K K}^{3}\right)}{|\lambda|}
$$

where $|\lambda| \equiv \pi \lambda_{1 L} \lambda_{3 K}-\lambda_{1 K} \lambda_{3 L}$, which must now be positive by the Neary stability condition (hence the need to consider a capital-intensive processing sector in this archetype). Establishing the sign of this expression requires us to impose a further stability condition. Equation (16a) is of ambiguous sign. $|\theta|>0 \Leftrightarrow \theta_{3 K^{\prime}} /\left(\theta_{2 L} \theta_{32}\right)>\theta_{1 K^{\prime}} / \theta_{1 L}$. In words, if the ratio of capital to the indirect labor content of good 3 is less than the capital labor ratio of good 1, the return to natural resources would rise with a fall in price of good 2. However, this implies a downward sloping supply in 2 since by (17) we would have a rise in output. Using (15a) and (16a), it can be seen that to rule out this possibility requires:

$$
\frac{\theta_{3 K}}{\theta_{32}\left(\theta_{2 N}+\theta_{2 L}\right)}>\frac{\theta_{1 K}}{\theta_{1 L}}
$$

i.e., the ratio of capital requirements to the sum of indirect factor requirements must exceed the capital-labor ratio of good 1. For stability we require production of good 3 to be capital intensive relative to good 1 in this sense, and hence $\hat{n}<\hat{w}<0$. This condition is also sufficient to ensure that (19b) is positive. Exports of good 2 therefore contract as before, so the Harberger effect is negative. Hence, $d W / d t$ is unambiguously negative. In the absence of foreign ownership, there is a monotonic 
and negative relationship between social welfare and the rate of the export tax.

PROPOSITION 7: In stable equilibrium with urban processing, foreign ownership of the natural resource still provides a potential rationale for export restrictions.

PROOF: This final result relies on (16a), which when combined with the condition (20) ensures that $d n / d p_{2}>0$. Hence, from (12) if foreign ownership is present, the overall welfare effect will depend on whether the negative effects on employment possibilities and the deadweight loss are outweighed by the investment terms-of-trade effect. However, while possible, it is important to note that there can be no general presumption that this will be the case. $\square$

Hence, the employment effect of an export tax will take the opposite sign depending on where the processing industry is located. This result does not depend on factor intensities. However, once we impose appropriate stability conditions (in terms of the factor intensities) on our two archetype models, we ensure that the Bhagwati-Tironi result holds in either case. Of course, we can only compare the signs of the welfare changes. In the urban processing case we have $L_{U}=L_{3}+U$ where $U$ is the total number of unemployed, as opposed to $L_{U}=L_{1}+U$ in the rural case, which will not be the same in general.

\section{Concluding Comments}

Intuitively these results are quite appealing. It seems natural that if the processing activity is located in the rural area along with the raw material industry, processing incentives should provide more opportunities for rural workers, and stem the tide of migration to the urban sectors. This is welfare enhancing. On the other hand, if the processing industry is located in the urban sector and is capital intensive, export restrictions encourage rural capital outflow and workers to move to the urban sector, worsening the unemployment problem. This reflects the fundamental importance of job creation policies in the HT framework. It is not processing itself that is welfare improving, but rather creating opportunities for the rural labor-force to be employed instead of joining the mass of urban unemployed. Thus the long-run result of Dean and Gangopadhyay (1997), which implies that export restrictions in the HT framework are likely to lower unemployment, needs to be qualified. Much depends on the assumed structure of the economy, in particular where the processing industry is located. In the case of foreign owned resources, however, the results do support the contention that export restrictions will result in a positive investment terms-of-trade effect, irrespective of where the 
industry in located. Of course, we are dealing here with second-best interventions. The first-best policy response remains the elimination of the wage distortion, and, if taxing the income streams of foreign capital is desired, a direct tax on foreign capital.

\section{Acknowledgement}

We would like to thank an anonymous referee for helpful comments. Foreign Capital, Processing Incentives, and Urban Unemployment

Date accepted: July 18, 2001

\section{References}

Batra, R.N. and Casas, F.R. (1973), "Intermediate Products and the Pure Theory of International Trade: A Neo-Heckscher-Ohlin Framework" American Economic Review 63(3):297-311.

Bhagwati, J.N. and Tironi, E. (1980), "Tariff Change, Foreign Capital and Immiserization: A Theoretical Analysis" Journal of Development Economics 7(1)71-83.

Brecher, R.A. and Diaz-Alejandro, C.F. (1977), "Tariffs, Foreign Capital and Immiserizing Growth" Journal of International Economics 7(4):317-22.

Chao, C.C. and Yu, E. (1996), "Optimal Policies of Taxation on Foreign Investment and Export Performance Requirements" Public Finance 51(2): 201-16.

Chao, C-C. and Yu, E.S.H. (1999), "Export Promotion, Sectoral Unemployment, and National Welfare" International Economic Journal 13(4):1-15.

Chao, C-C. and Yu. E.S.H. (1992), "Imported Materials Prices, Urban Unemployment, and Welfare" International Review of Economics and Finance 1(2):121-32.

Dean, J.M. and Gangopadhyay, S. (1997), "Export Bans, Environmental Protection, and Unemployment" Review of Development Economics 1(3):324-36.

Gilbert, J. and Wahl, T. (2001), "Export Restrictions, Urban Unemployment, and the Location of Processing Activities" Economics Letters 71(1):105-110.

Harris, J.R. and Todaro, M.P. (1970), "Migration, Unemployment and Development: A Two-Sector Analysis" American Economic Review 60:126-42.

Marjit, S., Broll, U. and Mitra, S. (1997), "Targeting Sectors for Foreign Capital Inflow in a Small Developing Economy" Review of International Economics 5(1):101-6.

Neary, J.P. (1981), "On the Harris-Todaro Model with Intersectoral Capital Mobility" Economica 48:219-34. 